\title{
R.D. Gidney and W.P.J. Millar How Schools Worked: Public Education in English Canada, 1900-1940
}

Montreal and Kingston: McGill-Queen's University Press, 2012. xvii, 517 pp.

\section{Thomas Fleming}

University of Victoria

Robert Gidney and Wyn Millar, long regarded as two of the nation's preeminent historians of education, have set themselves a difficult but worthy task - reconstructing the real world of public schools in English-speaking Canada from the end of the nineteenth century to the middle of the twentieth century. In explaining their purpose, they write: "To those who have tended to dismiss the early twentieth-century school as the home of mindless rote, drill, and irrelevance, or, under the spell of a romanticized afterglow, cast it as a model of focused purpose, high academic standards, public accountability for achievement, and communal solidarity, we want to invite contemplation of more tempered and nuanced assessments" (xix). With this in mind, they build a finely textured portrait of an eventful historical era that employs a careful sampling of experiences to illustrate that Canada's educational story in Englishspeaking provinces was remarkably similar in its expression from the Maritimes to the Pacific between 1900 and 1940.

Drawing on an impressive collection of archival documents, interwoven with an arsenal of past and recent historical studies, the authors probe a series of questions across thirteen chapters that explore the broad contents of schooling, including: patterns of attendance; the character of schools as organizations; the characteristics, qualifications, and gender of the teaching workforce; the burdens and inequities of school finance; the organization of instruction; the measurement of educational progress; levels of participation in secondary education; and, how matters of educational quality were determined. Altogether, the study is nothing less than a tour de force that takes us on a journey into the inner linings of school organizations and inside the process of schooling itself from the ground up.

From an array of rich statistical descriptions we learn, for example: "How many 
children went to school, how often, for how long, and the range of their educational attainments. What and how were they taught? How were they assessed and promoted from grade to grade? What were the qualifications and experience of their teachers? What were their school buildings like? Who paid the bills and how much did they pay? ... And how did the answers to these questions change over time?" (xviii).

Thanks to such splendid data we are able to see with fresh eyes the main currents and developments that marked the modern school's development in the first half of the twentieth century, including: how irregular participation in elementary schooling characteristic of the nineteenth century gave way to patterns of regular attendance for eight or nine years for most children; why high school completion remained a dream for many before the middle of the twentieth century; why rural and workingclass youngsters were less likely to stay in school than urban and middle-class children and those from British backgrounds; why many youngsters at both ends of the compulsory age-range did not attend school, as well as many others excluded for mental, physical, or behavioural reasons; why high school educational credentials became more important as time progressed; how high school programs were broadened; how parents and teachers generally shared common instructional values; and, finally, how government policies, inspections, and examinations impacted on the quality of learning before mid-century. All in all, How Schools Worked provides both a finely observed and panoramic understanding of educational developments in English-speaking Canada from the close of the Victorian Age to the eve of the Second World War and slightly beyond.

Each of the chapters is carefully thought out and well written but a few warrant special mention. Chapter 6, "Money," is a topic inseparable from anything to do with public schooling yet is one rarely covered by historians of education, educational researchers, or social scientists. For the best part of fifty years, virtually no one in the education field has discussed money seriously, other than registering cries that "there's never enough of it," or "we could sure use more." In the data-free world that envelops public education, it has become axiomatic that schools require ever increasing funding, regardless of whether school populations rise or fall.

To their great credit, Gidney and Millar show us why money is important, how it conditions educational quality, educational opportunity, and the value society places on schools and learning. They lead us through critical questions that are normally the dark and often impenetrable domain of economists - who pays, who gets what, how school taxes and outcomes can be equitable or inequitable, why some property owners are required to make a greater tax "effort" than others to pay for schools, and just how much money was required at different points in the past to build and operate schools. As a primer in the basic economics of schooling, this is a "must read."

Likewise, Chapter 7, "The Crisis in Educational Finance: 1930-1939," provides an equally illuminating excursion across the largely unexplored continent of school finance. Here the authors examine the devastating effects of the Great Depression on the nation's schools, particularly those in rural areas where the hardships of the 1930s were so severe they shaped the consciousness of Canadians for decades to come. Not all communities were equally affected as Gidney and Millar demonstrate in their 
chronicle of how school board revenues evaporated as rural districts reverted to a barter economy, and how poor districts tried to cope by trimming services, salaries, and the length of school terms. This is another illuminating chapter where we learn how money and geography have shaped the variety of historical experiences in schools.

Chapter 11, "The Teacher's Work," presents a charming analysis of the professional lives of rural school teachers before mid-century. It describes the generic character of teachers' work, the trials of rural school teaching, the organization of classrooms and instructional patterns, and the challenges rural schoolteachers faced in presiding over what Gidney and Millar aptly term "a four-ring circus." This four-ring circus consisted of balancing lessons for children of different ages and abilities while organizing seatwork assignments for others, keeping beginners and older youngsters focused, and supervising playgrounds at recess while inscribing a new set of lessons or assignments on the blackboard. Teachers tried to do all these things for the most part with little normal school preparation, virtually no practice teaching in rural schools, and scant help from inspectors or supervisors of any kind. This is a fascinating chapter for any reader wishing to uncover the real world of schools and the historical struggles of teachers set firmly in time, place, and detail.

Finally, Chapter 12, "Supervisors and Their Work," offers a singularly important treatment of the supervisory corps in schools, consisting of inspectors (high school and elementary), superintendents, principals, their relationships with teachers, and the generally spotty and uneven nature of school supervision, particularly in rural schools, during the twentieth century's first four decades. From diverse archival sources and writings, Gidney and Millar furnish a national-level portrait of school managers simply unmatched in any other source. In particular, its description of school leaders should prove immensely valuable to students and professors of educational administration who remain in dire need of accurate and detailed descriptions of managerial work to offset the largely prescriptive and hollow character of much of what passes for administrative study in education.

In summary, How Schools Worked is an exemplary piece of research and writing and a sweeping work of historical scholarship. By every measure, this is a major study and one that promises to be of immense significance to the history of Canadian education for decades to come. In the portrait of the national educational experience it provides, and its uncovering of the very foundations of the public school itself, How Schools Worked has rightfully earned a place alongside other towering studies of Canadian schooling such as George Tompkins' A Common Countenance and Neil Sutherland's Children in English-Canadian Society. 